\section{Observación antropológica de los indígenas wayú en la región de La Guajira, Colombia (Suramérica)}

\author{
BLANCA YSABEL DAZA MARTÍNEZ ${ }^{1}$ \\ 0000-0002-4102-0556 \\ Universitat de Barcelona, España
}

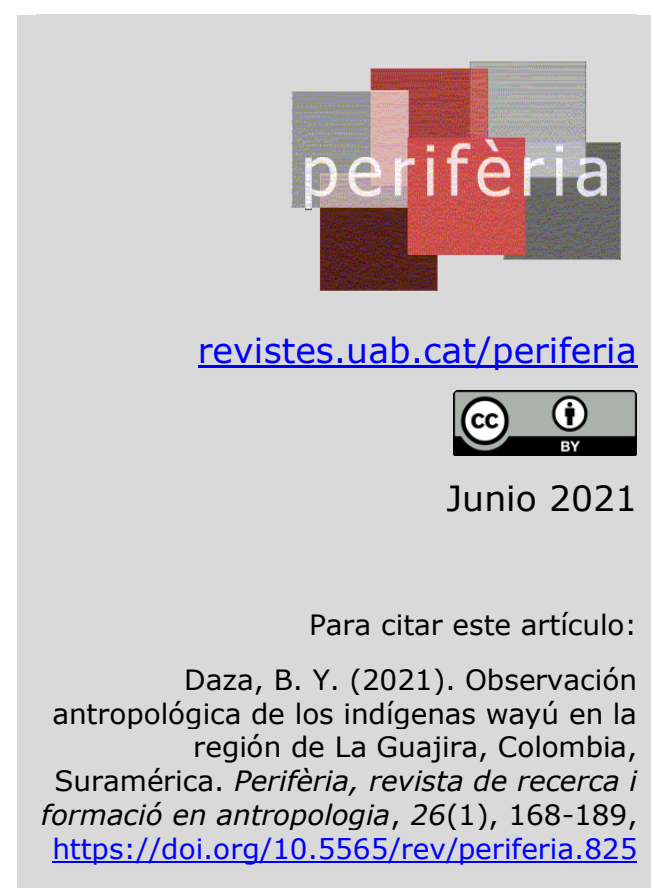

\title{
Resumen
}

Los indígenas wayú son una de las comunidades indígenas más numerosas de Colombia y, por lo tanto, una de las comunidades más representativas de este país. Se encuentran ubicados al norte de Colombia en un departamento llamado La Guajira. El presente texto recoge los apuntes etnográficos fruto del trabajo del campo llevado a cabo con dos comunidades de indígenas wayú: Cachaca I y Cachaca II. Durante la estancia etnográfica se hicieron varias visitas al territorio con el fin de interactuar con los niños, las mujeres y los ancianos. El objetivo principal de la labor fue recoger los testimonios y conocer de primera mano sus tradiciones, sus creencias, su cultura, su forma de alimentarse y su manera de vivir.

Palabras clave: Colombia; Indígenas wayú; Cultura; Costumbres; Alimentación; Desnutrición.

\section{Abstract: Anthropological observation of Wayú indigenous from La Guajira, Colombia (South America)}

The Wayú indigenous people are one of the most numerous indigenous communities in Colombia and, therefore, one of the most representative communities in this country. They are located in the north of Colombia in a department in a department

\footnotetext{
${ }^{1}$ Contacto: Blanca Ysabel Daza Martínez - blancaysabeldm@hotmail.com.
} 
called La Guajira. This text collects the ethnographic notes resulting from field work carried out with two Wayú indigenous communities: Cachaca I and Cachaca II. During the ethnographic stay, several visits were made to the territory in order to interact with children, women and the elderly. The main objective of the work was to collect the testimonies and learn first-hand about their traditions, beliefs, culture, their way of eating and their way of life.

Keywords: Colombia; Indigenous Wayú; Culture; Traditions; Feeding; Malnutrition.

\section{Los indígenas wayú}

Los indígenas wayú habitan los alrededores de Uribía, la serranía de Jala 'ala y las sabanas de Wopu'muin en los municipios de Maicao y Manaure del departamento de La Guajira, Colombia, Suramérica. El wayunaiki (idioma de los wayú) pertenece a la familia lingüística arawak. La lengua representa para ellos un importante factor de identidad étnica y cultural.

El asentamiento tradicional guajiro consiste en un grupo de cinco o seis casas que conforman caseríos o rancherías llamadas piichipala. Cada ranchería tiene su nombre propio en wayunaiki, que bien puede ser el nombre de una planta, de un animal o de un lugar geográfico. A las aldeas que conforman las rancherías las designan con el apellido transmitido por matrifiliación; por ejemplo, la tierra de los Uriana es propiedad solamente de los miembros de esa casta.

Todos los residentes de un asentamiento guajiro pertenecen a una serie o agrupación determinada de parientes uterinos. Cada serie de parientes se agrupa en cada ranchería donde los miembros comparten derechos y recursos en común, sea la huerta, el pozo o un cementerio. Tienen una red de estrecha colaboración. Los vínculos sociales de parentesco y afinidad son los criterios decisivos que vinculan todas las casas a una determinada unidad social (Daza y Tobar, 2006). 


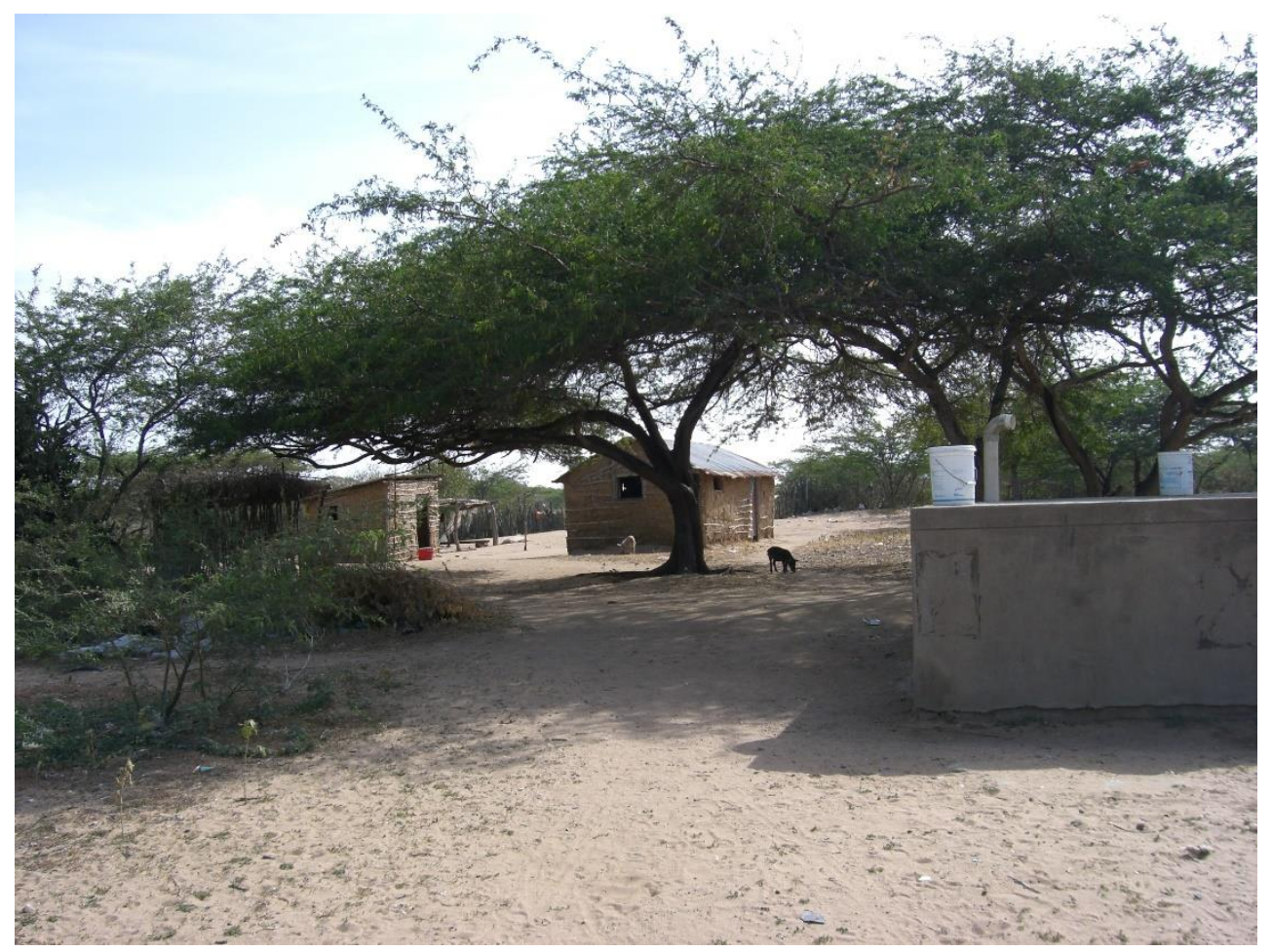

Imagen 1: Ranchería en la Cachaca I. (c) Blanca Ysabel Daza Martínez, 2006.

\section{Observación de los indígenas wayú de Cachaca I y Cachaca II (sector}

\section{Playa)}

El trabajo de observación de los habitantes de la comunidad indígena wayú es verdaderamente interesante. En cada visita, en cada vivencia con los integrantes de la comunidad aprendo una lección diferente.

La mayoría de las mujeres de la comunidad son muy jóvenes, pero aparentan más edad de la que dicen tener. Tienen el cabello muy oscuro y largo y siempre lo llevan recogido con una pinza de metal negro. Para ellas el cabello largo es fundamental, es como un símbolo de mujer bella y de feminidad. Cuando inician la pubertad (la 
primera menstruación), la madre, la abuela o la persona que tenga la obligación ${ }^{2}$ procede a hacer los preparativos del encierro, construyéndole al lado de la choza un ranchito especial para la niña, una celda aparte. Ponen un tabique al cuarto de la choza donde será el lugar del recogimiento de la muchacha, quien es encerrada de cuatro a seis días. La ceremonia se inicia rapándole el cabello a la niña y se sigue una serie de rituales. El objetivo final es sacarle los malos humores a la pequeña, prepararla para la llegada de la pubertad y que se convierta en una señorita bien hermosa.

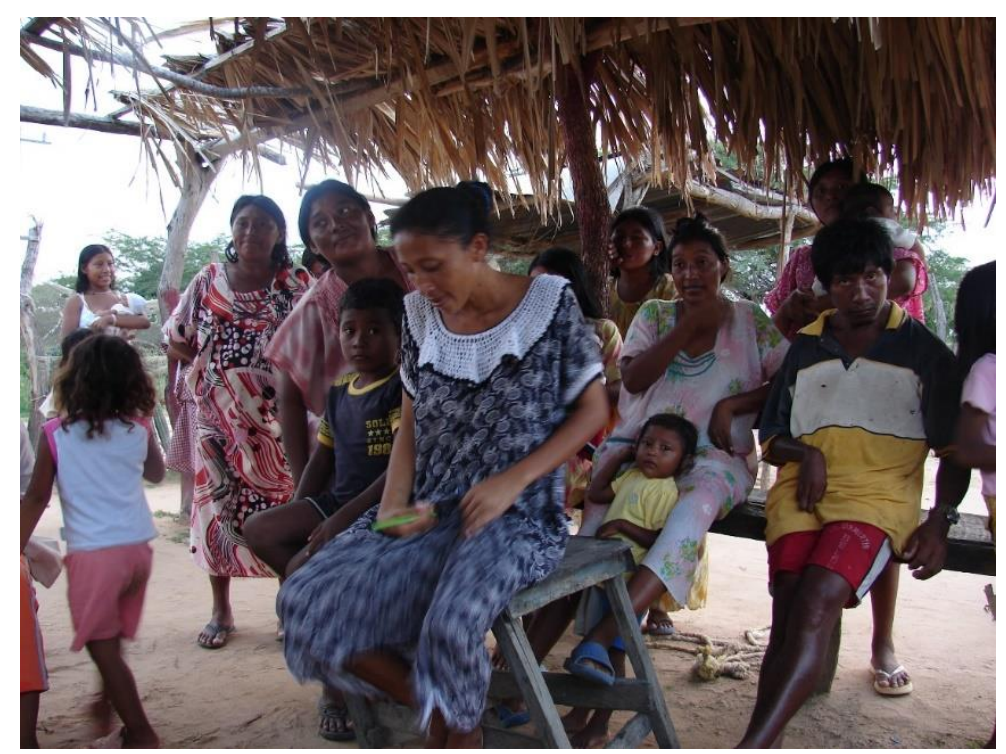

Imagen 2: Reunión con las mujeres de la ranchería. (c) Blanca Ysabel Daza Martínez, 2006.

Las mujeres de la tribu visten mantas de colores vivos, fuertes, alegres y muy anchas, porque así es más fácil para dar el pecho a sus bebés, cosa que hacen a todas horas del día, en cualquier lugar donde les va bien, normalmente sentadas sobre sus piernas, manera muy peculiar que tienen de sentarse bajo las enramadas.

\footnotetext{
2 En La comunidad indígena Wayuu, la ceremonia que realizan con las niñas cuando inician la pubertad, solo la pueden llevar a cabo las mujeres de la comunidad. Cuando hablan de obligación se refiere a quien está a cargo de la niña, puede ser la abuela, la madre, la tía, o la hermana mayor. Siempre familiares por parte de la madre.
} 
La enramada, choza o "chavola" está hecha con cuatro palos puestos verticalmente y el techo cubierto con ramas y, a veces, con yotojoro (material que se extrae del cactus), así se protegen del sol, del calor agobiante y de la humedad tan elevada. Habitualmente van descalzas, muy rara vez llevan chancletas (especie de sandalias) y, si las usan, son negras y de un plástico bastante duro.

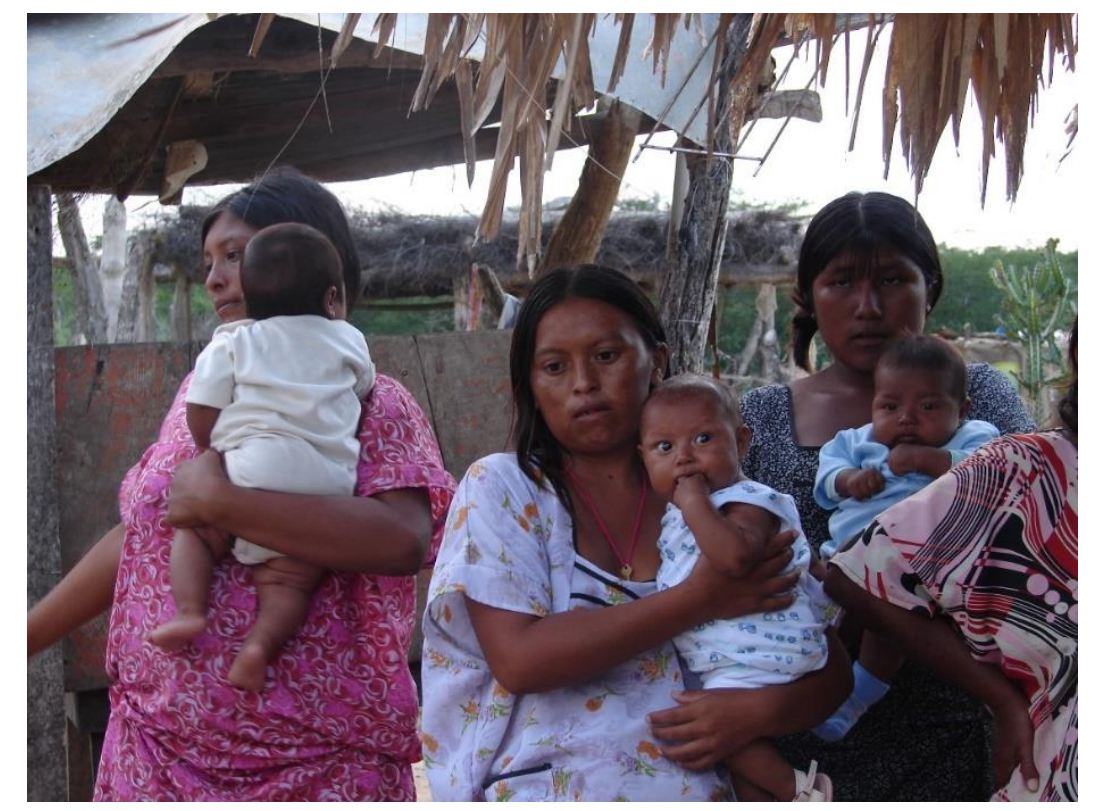

Imagen 3: Las madres con los bebés. (c) Blanca Ysabel Daza Martínez, 2006.

La mujer wayú ocupa un lugar muy importante en la comunidad, ya que es ella la que se encarga de todas las labores de la casa (piichi). Cuida de sus hijos, que normalmente son cuatro o cinco y todos muy pequeños; a veces amamanta a dos de sus pequeños a la vez. Arregla la choza y sus alrededores para que esté más o menos ordenado: barre con un rastrillo y una pala, ya que todo lo que recoge es tierra amarilla y arena; desmonta las hamacas donde han pasado la noche; dobla la ropa y la pone en un rincón ya que allí no existen los armarios para guardarla. La mayoría de las viviendas solo tienen una habitación de unos tres metros de ancho por cuatro de largo. Aquí, en este espacio, colocan sus hamacas o chinchorros y duermen todos los miembros de la familia, que pueden ser siete u ocho. Tres o cuatro personas duermen en una hamaca, y los bebés encima de sus madres. La mujer wayú también se encarga de cocinar para toda su familia, de lavar los cacharros (enseres) de la 
cocina con agua que recogen en un platón de plástico, de limpiar los peces que ha pescado el marido la noche anterior y es ella la que los lleva caminando a Riohacha, la ciudad más importante de la región que está a $4,5 \mathrm{~km}$ de la ranchería, para venderlos en la plaza del mercado.

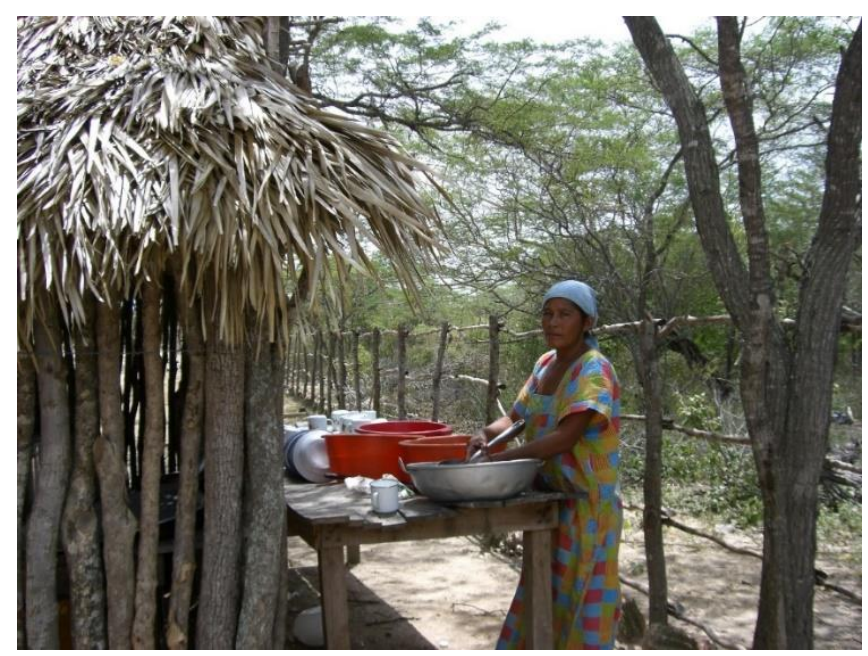

Imagen 4: Mujer indígena wayú lavando los cacharros de la cocina. @ Blanca Ysabel Daza Martínez, 2006.

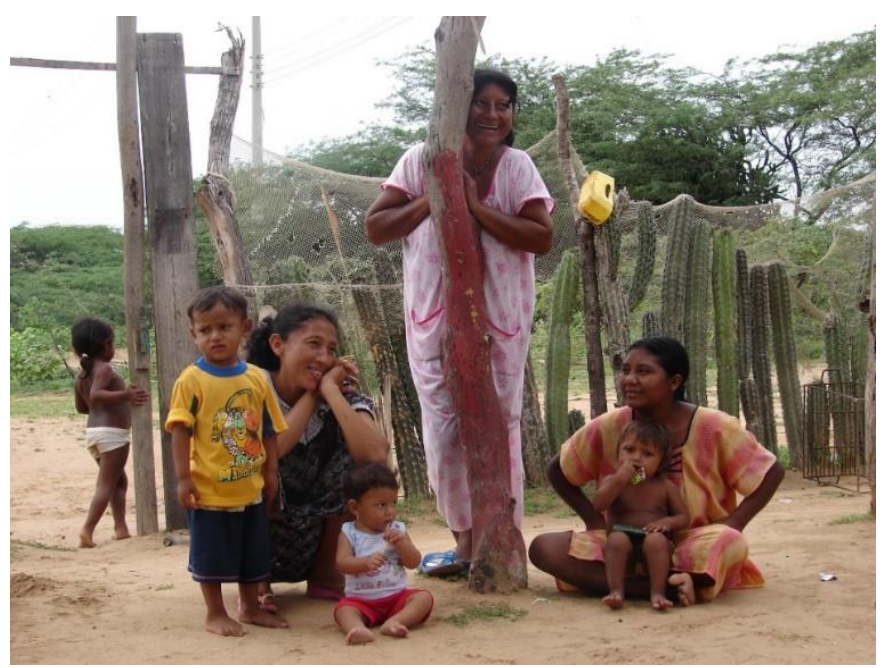

Imagen 5: La mujer wayú siempre cuida de sus hijos. @ Blanca Ysabel Daza Martínez, 2006. 
Los hombres se dedican sobre todo a la pesca artesanal y algunos a la agricultura, actividad bastante dura y difícil en esta zona ya que las condiciones no son aptas para la agricultura extensiva. Solo llueve en los meses de noviembre a enero. El resto de los meses es un clima semidesértico, llegando a temperaturas de 40 grados. Por lo tanto, durante la estación de lluvias los hombres de algunas familias siembran yuca, maíz, patilla y calabaza.

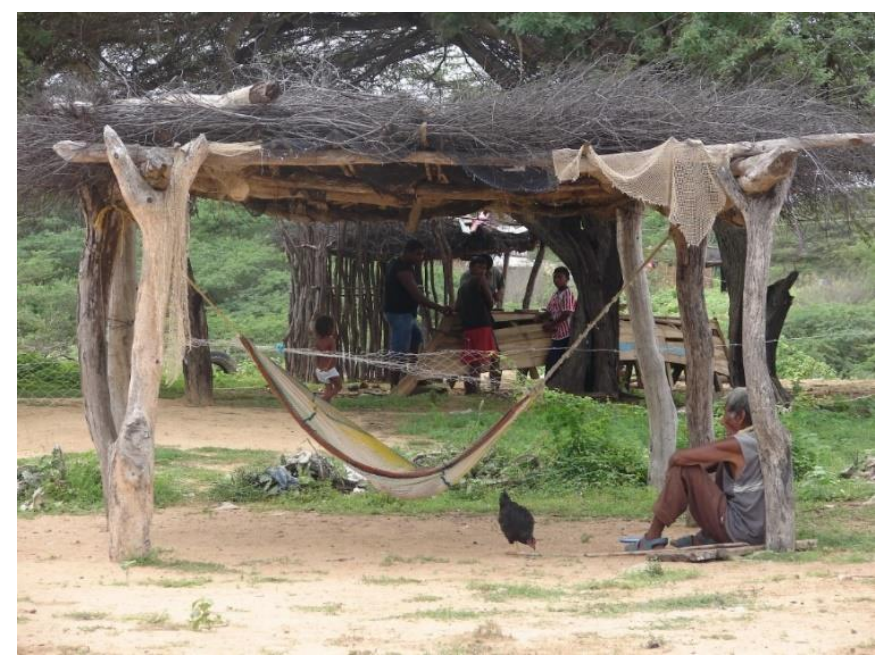

Imagen 6: Enramada con hamaca. Al fondo, hombres preparando una barca para la pesca. (c) Blanca Ysabel Daza Martínez, 2006.

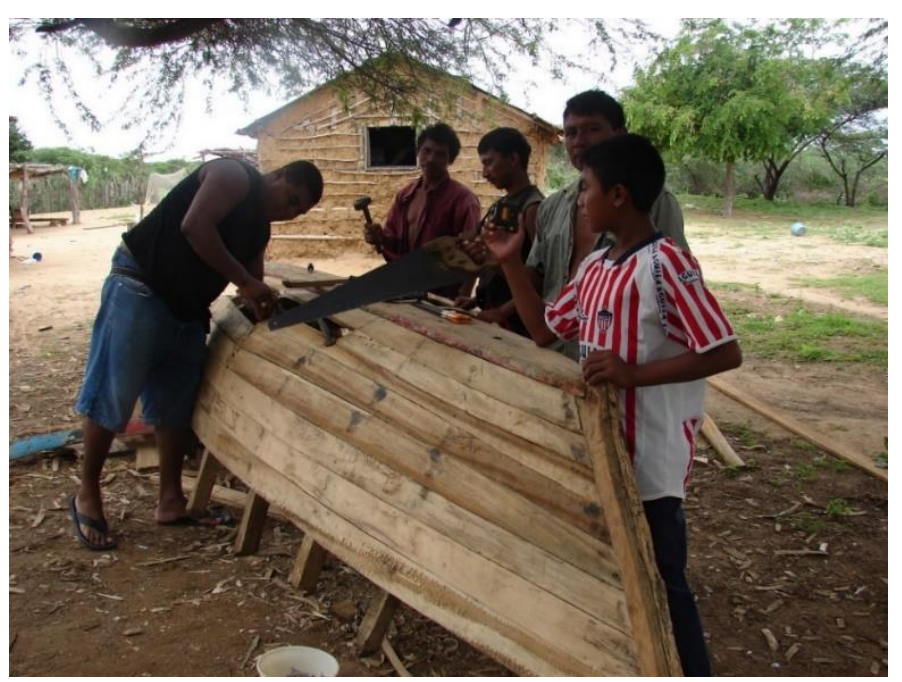

Imagen 7: Hombres de la ranchería preparando una barca para la pesca. (c) Blanca Ysabel Daza Martínez, 2006. 


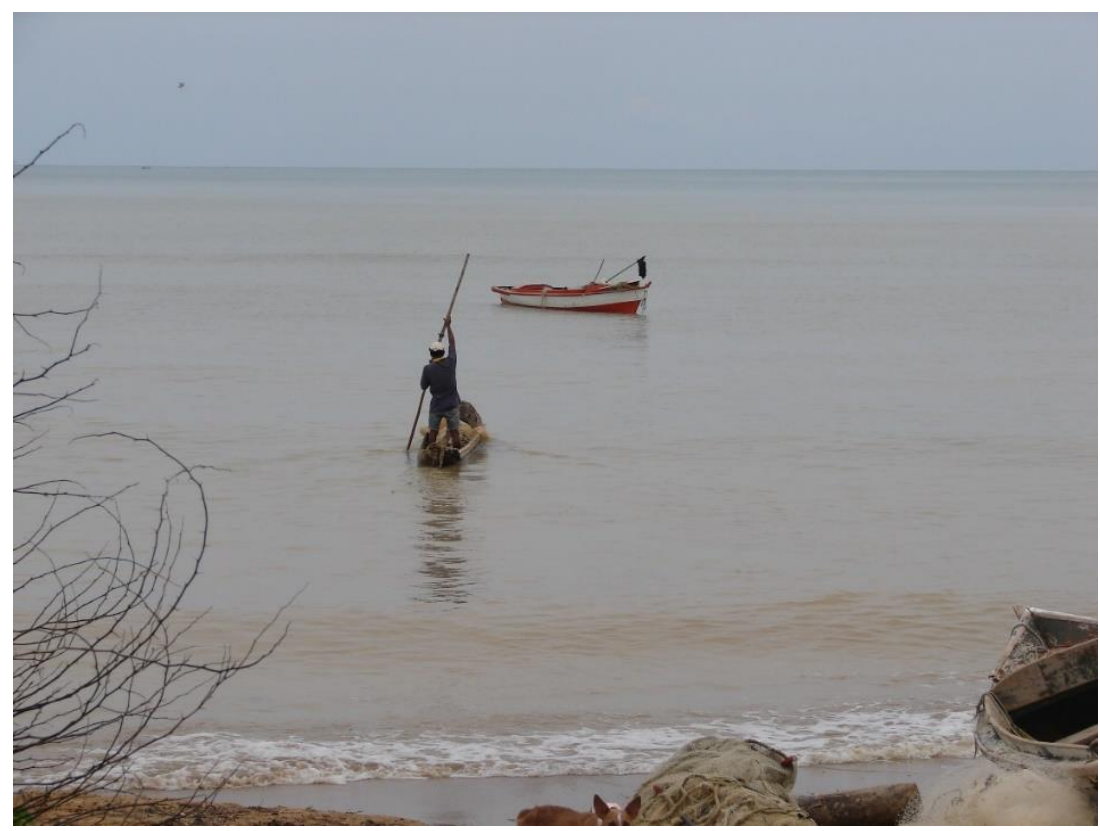

Imagen 8: Hombre de la comunidad iniciando la labor de la pesca. (c) Blanca Ysabel Daza Martínez, 2006.

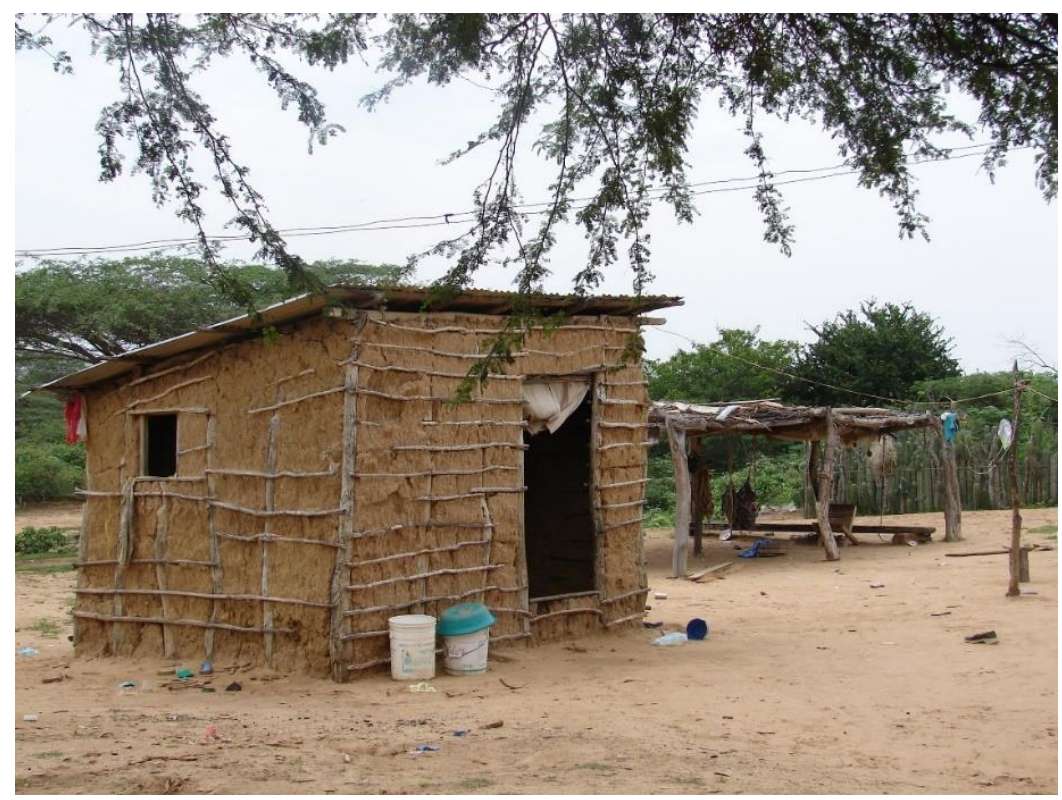

Imagen 9: La casa de una de las familias. (c) Blanca Ysabel Daza Martínez, 2006. 
La casa donde siempre me acogen es la choza de Fidelina Epiayú, casada con un alijuna, que en el idioma wayú es el nombre que se le da a toda persona ajena a la comunidad. Es el sitio donde descargo mis pertenencias y consumo lo que ellos humildemente me brindan, normalmente arroz, plátano frito y chirrinche, bebida fermentada que elaboran a base de maíz y panela.

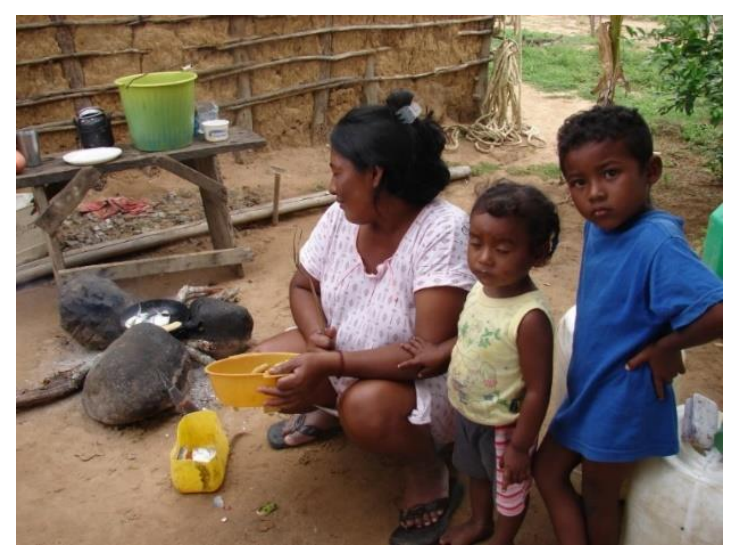

Imagen 10: Fidelina con dos de sus hijos. (c) Blanca Ysabel Daza Martínez, 2006.

El marido de Fidelina, Elder, es afrodescendiente e indica su origen en la Costa Atlántica. Esta es una familia que se diferencia de las otras precisamente porque el esposo no es wayú. Pocas personas en la ranchería están casadas con un/una alijuna porque, según las tradiciones, se han de casar con un miembro de la misma comunidad y, de ser posible, que sea de la misma familia.

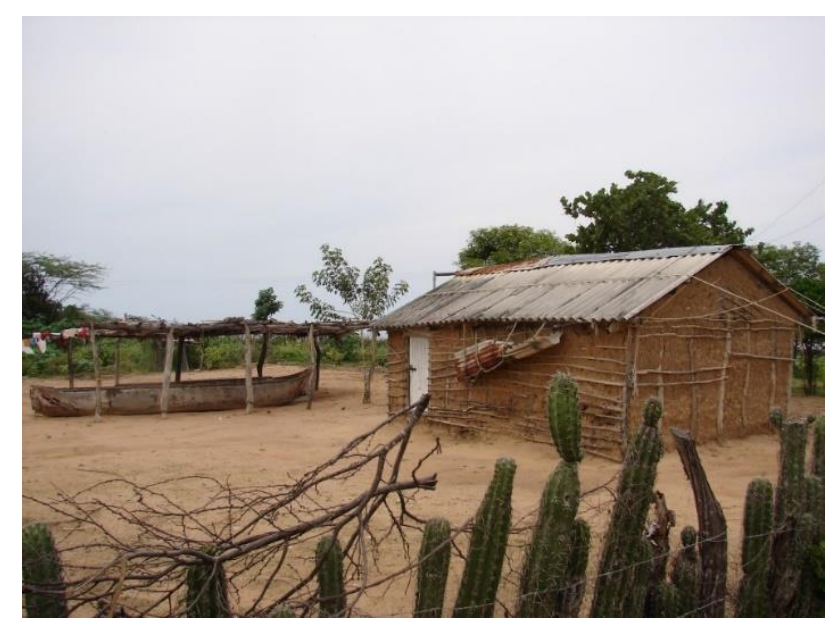

Imagen 11: Ranchería wayú rodeada de cactus. (c) Blanca Ysabel Daza Martínez, 2006. 
La choza de Fidelina y Elder está rodeada de cactus porque así la protegen de la arena del desierto y los posibles animales que puedan acecharla. Tiene dos habitaciones. En una duerme toda la familia, que consta de siete miembros: ellos dos y cinco hijos de siete, seis, cinco y cuatro años y el menor de nueve meses. En la otra habitación tienen una tienda que está muy bien organizada y ordenada. En esta ellos venden harina de maíz, maíz en grano, pimienta, comino, atún en agua, aceite de maíz y de palma, sal, arroz, "ganchitos" (chucherías para los niños), pasta, picante, plátanos, bananos, cebolla larga (parecida a los calçots), tomate maduro, patatas, frutiño (bebida con sabor de frutas y un alto contenido de azúcar), panela y hielo. También venden productos de limpieza, papel higiénico y medicamentos, que están expuestos al lado de los productos de alimentación en un estante contiguo. Entre los medicamentos encontré sal de frutas para los problemas estomacales, acetaminofén para niños y para adultos, ibuprofeno y amoxicilina en jarabe, que utilizan cuando creen que un niño puede tener alguna infección grave por la picada de un insecto y que no pueden curar con sus plantas medicinales, tales como las hojas del árbol de matarratón y de dividivi.( al cual ellos le dan muchas propiedades, como la de prevenir infecciones), Estas hojas son hervidas y aplicadas en la piel cuando sufren alguna picadura de mosquito o de cualquier otro insecto.

Observé que cuando un niño "se pone malo" y los remedios caseros que normalmente receta el piache (miembro de la comunidad al que se le atribuye magia y poderes para curar con sus pócimas y brebajes) no han funcionado, van a la tienda de Fidelina y aquí les venden la cucharadita de amoxicilina a 200 pesos (unos 0,047 euros). Los demás medicamentos también se venden por pastillas o unidad.

Lo que me pareció más curioso es que durante todo el día, tanto mujeres como niños, acuden a la tienda para hacer sus compras. En esta hay una báscula donde lo pesan todo y donde es habitual comprar por poquitos: un tomate, una patata, 70 gramos de arroz o de azúcar. Nunca compran una botella entera de litro de aceite, sino que lo vierten en otra más pequeñita de $50 \mathrm{~mL}$, que se vende a 300 pesos (unos 0,071 euros).

Debido a que el marido de Fidelina es alijuna, la familia tiene unas costumbres y tradiciones menos arraigadas cuando se comparan con las de otras familias típicamente wayú. Por ejemplo, uno de los domingos que estuve allí vino la familia de Elder y todos juntos prepararon la comida. Hicieron una comida típica de la Costa 
Atlántica: sancocho de pescado (bagre), que es como una escudella catalana, hecho con plátano, patatas, tomate, cebolla y condimentos. También bebieron cerveza.

Normalmente todos los habitantes de las rancherías son familia por parte de madre, y en estas familias todos sus habitantes tienen el mismo apellido: Epiayú.

Fidelina y Elder son los únicos que poseen electricidad porque hicieron Ilegar un cable desde unos contadores que hay en la carretera. Es una instalación rudimentaria y peligrosa, pero al menos ellos tienen luz. Además, tienen televisión y muchas de las mujeres de las otras rancherías acuden durante el día a ver los programas de la cadena nacional; así, mientras tanto, aprovechan para sentarse y amamantar a sus pequeños.

Otras de sus pertenencias es una "cava de hielo" (como ellos la llaman). Es una caja de porespán de $80 \mathrm{~cm} \times 70 \mathrm{~cm}$ que mantienen llena de hielo. La caja la ocupan primero con hielo que compran en la gasolinera y luego agregan bolsas de plástico con agua no potable que cogen de la alberca, situada a unos tres metros de la choza de Fidelina. El propósito de estas bolsas es tener agua fresca para beber, a pesar de que no sea potable.

Un carrotanque de la ciudad de Riohacha viene cada tres semanas a llenar esta alberca (aljibe, que es como ellos la llaman usualmente). El agua dura más o menos una semana y cuando se acaba no hay agua para nada hasta que vuelve el camión otra vez y se repite la operación.

El agua en estas comunidades es muy escasa y, la poca que hay, no es potable. Existe un pozo situado a unos diez metros de la casa de Fidelina que solo recoge agua en las épocas de Iluvia. En las rancherías no hay baños, los habitantes de la comunidad van a sitios alejados para hacer sus necesidades fisiológicas.

Un día, hablando con Fidelina, le pregunté cómo es que ella, perteneciendo a los wayú, indígenas muy tradicionales y defensores de sus creencias, se había casado con un hombre ajeno a la comunidad, y ella me contó su historia. Cuando tenía 16 años se enamoró de Elder en la ciudad de Riohacha. Me contó que era un hombre casado y que tenía su propia familia. La familia de Fidelina no lo aceptó y los rechazaron, pues era una deshonra para toda la familia Epiayú. Ella se reveló ante toda la comunidad y se fue de la ranchería. Unos años más tarde, Fidelina y Elder vivían en un pueblo cercano a Riohacha. Ya tenían dos de sus cinco hijos cuando 
estaban pasando por una situación muy precaria. Entonces, ella decidió ir donde su familia para ver si podía regresar. Sus padres, tíos y hermanos le dijeron que podía volver con sus hijos y esposo, pero que no podría intervenir en los asuntos de la comunidad Epiayú. Así viven y ya llevan varios años. Fidelina es una mujer de 26 años, bastante calmada, sumisa y cariñosa, que hace todo lo que su marido dice. Lleva la tienda, todas las labores del hogar y cuida de sus hijos.

Cuando estuve allí, se interesó por saber cómo es la vida en otros países: que si es verdad lo que sale en la televisión referente a otros lugares sobre cómo se vive, lo que hacen sus habitantes, sobre los niños en otros países, que viven de manera diferente. Me comentó que esos son lugares que nunca podrá conocer y que le hubiera gustado mucho ver. Traté de explicarle, de una manera muy sutil, que todos nacemos en algún lugar que no hemos elegido, pero que en el mundo donde nos ha tocado vivir tenemos que hacerlo. Por alguna razón, que no sabemos cuál, estamos allí.

Los hombres de las rancherías visten pantalones cortos y algunas chancletas, aunque la mayoría van descalzos. Ellos solamente se ocupan de ir a pescar. Suelen realizar esta actividad en la madrugada hacia las dos o tres de la mañana en grupos de cuatro personas. Dicen que no pueden caber más en una barca porque esta no se desplazaría con rapidez y se hundiría. Las redes son muy grandes y están hechas de hilo. Cuando se rompen, son las mujeres de la comunidad las que las remiendan. Tienen redes especiales para la pesca de peces y otras más pequeñas y estrechas para pescar camarones y langostinos. Hay días en que la pesca va muy bien y se coge pescado para el consumo de ellos mismos y para vender en la ciudad de Riohacha, en la plaza del mercado donde ya tienen sus contactos para venderlos. Algunos días con los niños de la comunidad nos sentábamos a la orilla de la playa para esperar a los hombres cuando regresaban con la pesca. Los niños casi siempre me acompañan a donde quiera que voy porque muy pocos adultos hablan español y en la mayoría de los casos son los niños los que me hacen de intérpretes.

Los wayú no utilizan ni los camarones ni los langostinos para su alimentación porque prefieren venderlos en el mercado. El kilo de camarones lo venden a 4000 pesos (unos 0,95 euros) y los langostinos a 6000 pesos (1,42 euros aproximadamente). Lo que sí utilizan para su alimentación son los pescados más pequeños. Siempre los comen fritos en aceite de palma porque no conocen otra manera de prepararlos. Los 
demás pescados los limpian sacándoles las escamas y las entrañas, procurando que todos sean del mismo tamaño, los atan por la boca con una cuerda de plástico de color verde, poniéndolos de nueve en nueve, y así atados los llevan al mercado. Cuando los hombres de la ranchería llegan de pescar en la mañana, se acuestan a dormir y no se levantan hasta las cuatro o cinco de la tarde.

La venta de pescado en la plaza del mercado es esencial ya que es la única manera que tienen de obtener dinero para comprar en la tienda lo que necesitan, como otros productos de alimentación, limpieza y medicamentos.

Los miembros de la comunidad que se dedican a la agricultura arreglan sus terrenos poniendo alrededor de la huerta cardón guajiro (un tipo de cactus) para protegerlos de los animales que rondan por la comunidad, como gallinas, cerdos y chivos; de esta manera no les comen sus sembrados. En las huertas siembran maíz, yuca, mijo, ahuyama, patilla y, a veces, fríjol; solo a veces porque la semilla es muy cara y necesita de más cuidados que las otras plantas. Los que no se dedican a la agricultura, ni a la pesca, solo duermen, descansan o se sumen en sus pensamientos.

Con los integrantes de la ranchería mantuve varias reuniones para hablar de la importancia de la recolección de basura. Del modo más amable y propositiva que pude, les expliqué que era muy peligroso para la salud de ellos y de los niños la no disposición adecuada de la basura, que sería muy importante empezar a tener cuidado de no tirar desperdicios en medio de sus casas. Varios días estuvimos recogiendo basura en cubos de plástico que compramos expresamente para tal propósito y que se pusieron al lado de la cocina. La cocina es una enramada situada afuera de la casa hecha con cuatro palos de base y techo de yotojoro, que se extrae del cactus y recolectan en lugares cercanos. Cada familia dispone de su "cocina" independiente. 


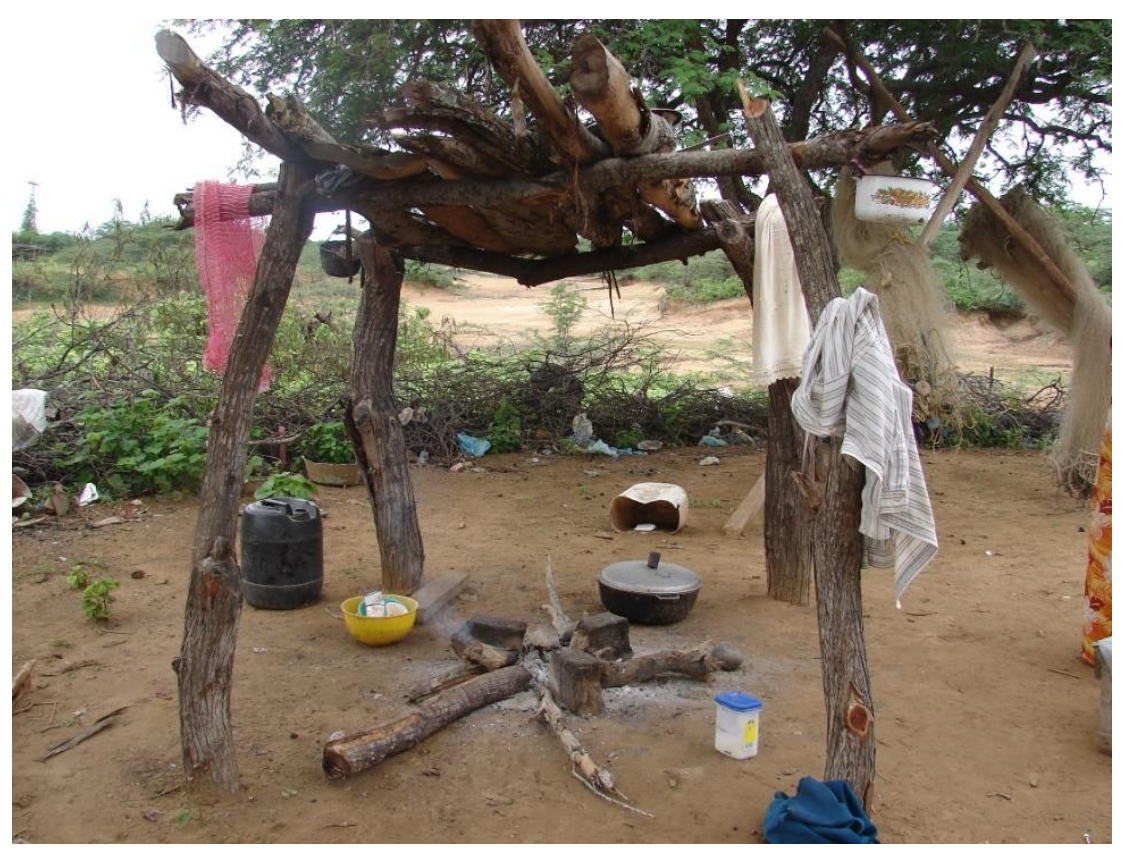

Imagen 12: Las mujeres de la comunidad preparan los alimentos debajo de la enramada.

(c) Blanca Ysabel Daza Martínez, 2006.

Los niños se levantan a las siete de la mañana para ir a la escuela que se encuentra en otra ranchería llamada Puerto Caracol, situada a 1,5 km de distancia. Muchos no llegan sino hasta las ocho u ocho y media porque han de hacer un largo recorrido caminando.

Durante varios días los acompañé a las aulas para ver cómo eran y cómo funcionaban. La escuela se compone de dos aulas. Hay aproximadamente 25 alumnos en cada una. En una de ellas los niños tienen de cuatro a ocho años. La profesora es wayú y, en los días que los observé, la maestra no se levantó de la silla. Eran los niños los que iban a ella para que les pusiese planas de tareas con vocales y números. Mientras los niños iban haciendo los deberes, ella hacía ganchillo sentada en su silla. En la otra clase los niños tenían entre nueve y dieciséis años. El profesor también era wayú y daba clases de diferentes materias a los niños, tales como matemáticas, geografía y ciencias. Los chicos se mostraban muy interesados en lo que el profesor les enseñaba.

La primera ingesta de los niños es un vaso de frutiño, que viene preparado en un sobre que venden en la tienda y que algunas madres por desconocimiento dan a sus 
niños de desayuno. Otras madres les dan un vaso de agua de panela, porque ellas confían que en el colegio les darán un desayuno más completo y saludable a sus hijos (Buen, 2004).

A las once de la mañana, los niños salen a desayunar lo que les ha preparado una mujer contratada por el ICBF (Instituto Colombiano de Bienestar Familiar) para esta labor. Ella es una indígena que pertenece a la comunidad wayú de Puerto Caracol. El desayuno consiste en un vaso de $50 \mathrm{~mL}$ de Bienestarina preparada con agua y una arepa de $60 \mathrm{gr}$, hecha con harina maíz y agua. A las doce, salen del colegio y se van a sus casas (Brazelton y Greenspan, 2005).

Hay otra escuela ubicada en la comunidad llamada Cachaca II. Los niños de esta comunidad no asisten a clases porque, primero, la escuela no está en condiciones de recibir niños por su mal estado (el techo de una de sus aulas se cayó hace dos años y todavía no lo han arreglado) y, segundo, porque la escuela está construida al lado de la choza de un anciano wayú y a él no le gusta el ruido que hacen los niños. A los pocos que van para recibir las clases no los deja en paz.

En Cachaca I solo un $10 \%$ de los niños va a la escuela, el resto pasa todo el día sin hacer nada, sin nadie que les enseñe ni les obligue a hacer alguna cosa. Pasan el tiempo en las rancherías jugando con lo que pueden o haciendo travesuras típicas de los niños de esa edad.

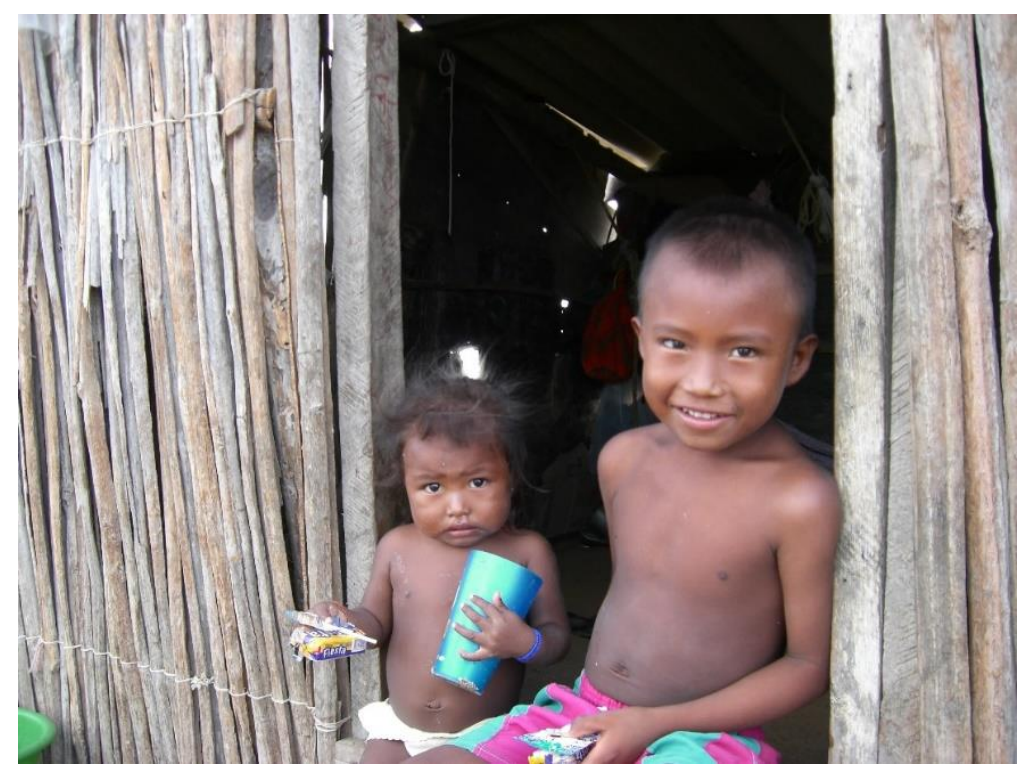

Imagen 13: Niños de la Cachaca I. @ Blanca Ysabel Daza Martínez, 2006. 


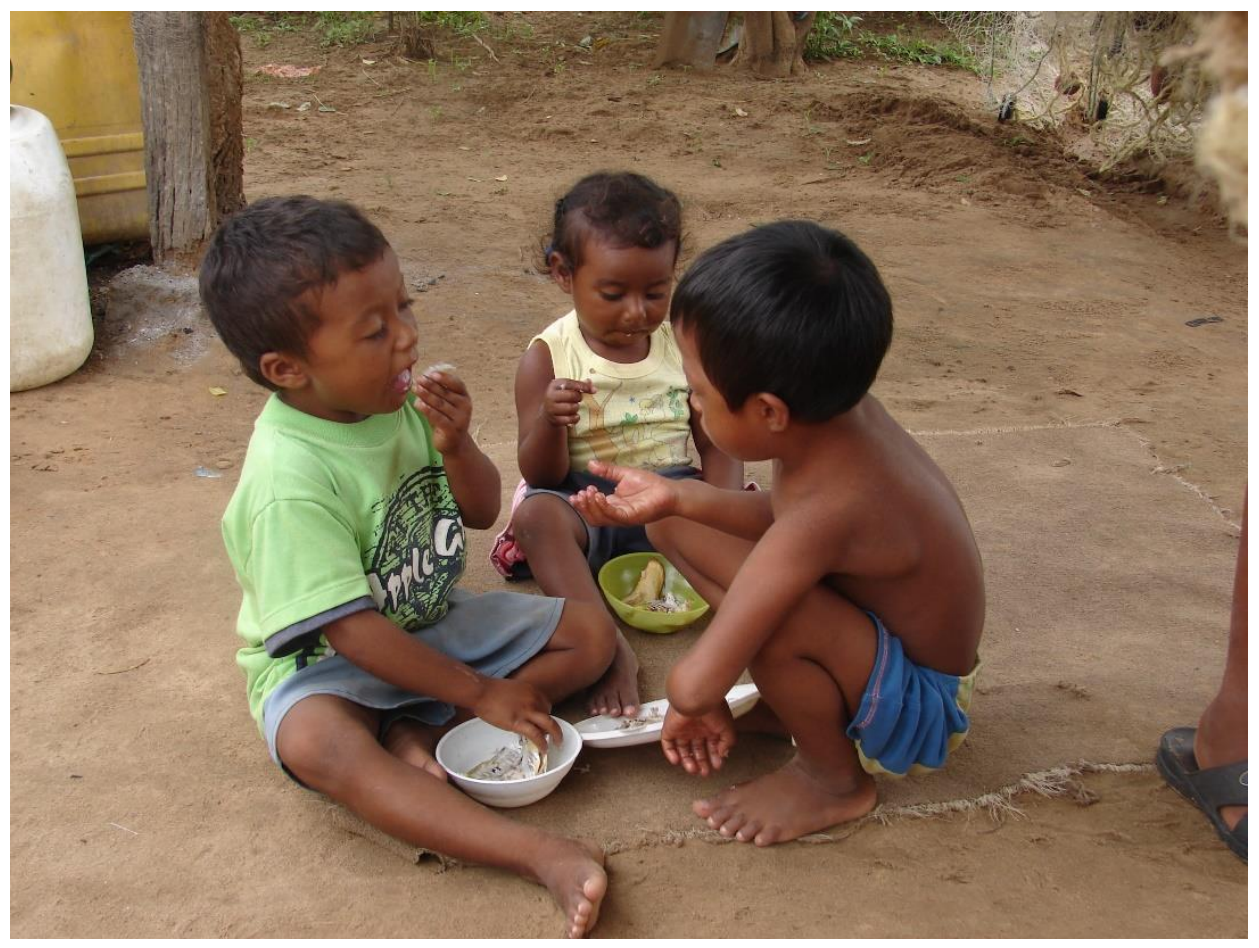

Imagen 14: Los niños de Fidelina. (c) Blanca Ysabel Daza Martínez, 2006.

Los niños mayores ayudan a sus padres a cuidar de sus hermanos más pequeños, a bañarlos, entretenerlos, teniéndolos cogidos en brazos todo el día ya que no hay otro sitio donde poner a los bebés. La mayoría de los pequeños se sientan a un lado de sus chozas, en la arena, totalmente desnudos. Algunos niños van con pantaloncillos y algunas niñas con bragas (las que las tienen o las que son un poco mayores). De otro modo, van desnudos, siempre descalzos y totalmente despeinados.

Un día tuve la oportunidad de llevar a la ranchería ropa para los niños y las niñas, zapatos de todas las tallas y colores y material escolar, como cuadernos, gomas para borrar, lápices, lápices de colores, reglas, plastilina, tizas y sacapuntas para todos los niños. Quise comprobar cómo se comportaban y si eran perceptivos a la hora de enseñarles. Me dejaron muy asombrada: ponían mucha atención a lo que les enseñaba y, además, manifestaban una gran curiosidad por saber más y más cosas. A partir de entonces, los sentaba todas las tardes debajo de una enramada y estudiaba con ellos, de tres a cuatro horas cada día. Al cabo de quince días ya no tenían cuadernos y tuve que adquirir más material escolar. En cuanto llegaba a la ranchería, todos los niños salían a recibirme con sus cuadernos en la mano para que 
nos sentáramos a estudiar. Tenía que repetirles que las clases eran por la tarde. Debo decir que cada día había más y más niños (parecían brotar de debajo de las piedras, como las setas salen de debajo de la tierra). Empecé con 20 niños y acabé con 180. Todos eran muy cariñosos y juiciosos, y cada vez querían aprender más. Creo que lo que los niños necesitaban era una persona que se interesará por ellos y les prestará atención a sus necesidades e inquietudes.

Una niña de seis años vino corriendo hacia mí el día en que me marchaba para Bogotá, diciéndome:

-Señorita Blanca Nieves -así es como me llamaban, porque dicen que soy muy blanca y no porque alguien les hubiera leído el famoso cuento de los hermanos Grimm de Blanca Nieves y los siete enanitos-, ¿cuándo va a regresar?

Le contesté que regresaría dentro de tres meses. La niña me preguntó:

-Pero eso en días, ¿cuánto es?

Le respondí:

-Más o menos noventa días.

Entonces me pasó su cuaderno y me dijo:

-Señorita Blanca Nieves, entonces, póngame las tareas para noventa días.

Todos los niños vinieron detrás para que a ellos también les pusiera más tareas (deberes).

Otra de las cosas que me causó mucha curiosidad es que, en ocasiones, todas las mujeres y los niños se sientan bajo la sombra en su enramada: las hijas van despiojando a las madres, las madres a las abuelas y estas a los nietos.

Una experiencia que pude vivir y que fue excepcionalmente emocionante fue el parto de una de las niñas indígenas de la comunidad. Como cada día, llegué a las ocho de la mañana. Todas las mujeres de la comunidad se mostraban agitadas: unas calentaban agua con hojas del árbol dividivi, otras se apresuraban a conseguir trapos de vestidos viejos o camisetas, ya que ellos no disponen de sábanas. Les pregunté qué pasaba y contestaron que G. Epiayú (joven wayú de 16 años) estaba de parto. Le solicité a la madre de la niña si podía asistir al alumbramiento y ser partícipe en 
el acontecimiento. Me respondieron que debía preguntarlo a la abuela de la parturienta. Le pregunté y me respondió que sí.

G. Epiayú estaba en un rincón de la choza tendida en el suelo sobre unos trapos viejos; casi no se sentía ningún ruido. A su lado estaban su madre, su abuela, su tía por parte de madre y yo.

Al principio, yo solo miraba el ritual de preparación de la parturienta para el momento de dar a luz a su hijo: la madre le apretaba el vientre, la abuela con sus dedos le ayudaba a preparar la zona íntima de la vagina, comprobando los centímetros de dilatación, y la tía la limpiaba con trapos húmedos y calientes con agua de dividivi. Después hice lo que ellas me decían, ayudando a la abuela, que en todo momento estaba muy relajada y tranquila. Tomando ejemplo de esto $y$, aunque estaba aterrada, no lo demostré, tomé aire y calmadamente observé y disfruté lo que estaba viviendo. Todo este ritual se demoró cuatro horas. La parturienta lloraba y se quejaba de dolor; tomaba aire de cuando en cuando, diciendo que las contracciones eran muy seguidas (cada cuánto era imposible de saber, pues allí no hay relojes para medir el tiempo; yo tampoco lo llevaba). Me esperaba que, sin ningún tipo de medicamento para contrarrestar los dolores típicos del parto, G. Epiayú gritara más, indicando que el momento de dar a luz se acercaba, pero no fue así: llegó un punto en el que ella estaba muy tranquila y escuchaba las palabras que, me imagino reconfortantes, iban pronunciando las tres mujeres en wayunaiki.

Al cabo de cuatro horas nació el bebé. Lo acogí en mis brazos. Lo limpié con los trapos viejos que me dieron humedecidos en el agua hervida de dividivi. No lo pude aspirar como es costumbre en cualquier hospital. Afortunadamente, todo salió bien. La madre estaba muy contenta pues era su segundo hijo. El padre del niño y el resto de los familiares estaban también felices.

Las mujeres de esta comunidad indígena no practican ningún tipo de prevención para no tener hijos. Dentro de sus creencias está que las mujeres pueden concebir hasta que les llegue el periodo de la menopausia, hasta entonces, pueden concebir niños y sus maridos pueden tener relaciones sexuales con ellas. Una mujer fértil que concibe hijos es importante para el hombre wayú porque representa que es joven, vigorosa y apetitosa sexualmente; de lo contrario, no vale mucho para el esposo, porque significa que se hizo mayor. 


\section{Alimentación}

Como se ha dicho, la alimentación de los indígenas wayú de las rancherías Cachaca I y Cachaca II es bastante invariable e insuficiente nutricionalmente. Siempre ha sido así. Se alimentan principalmente de arroz y plátano frito (García, 2003). Su plato tradicional es "el frichi", que está hecho con chivo frito en su propia grasa. No se come frecuentemente porque en las rancherías no se dedican a la crianza de cabritos y quienes los crían lo hacen para venderlos en el mercado o para brindarlos en alguna ocasión especial, como para darlos de dote cuando una hija se casa o cuando alguien importante de la comunidad muere, pues para honrar al muerto se invita a todos los integrantes de las comunidades vecinas a una gran comilona. Ese es su modo cultural de despedirse de la persona que ha dejado este mundo. El chivo es símbolo de riqueza, respeto y poder.

Mientras estuve con ellos pude constatar que la única fuente de proteína proviene del pescado, alimento que no consumen diariamente sino de vez en cuando. Las gallinas y los cerdos no los comen ya que los consideran animales inmundos y sucios y los crían para venderlos en el mercado. Los niños de la comunidad indígena wayú no ingieren ningún producto lácteo: ni leche, ni derivados lácteos como yogures, mantequilla, margarina, ni queso.

Los wayú no comen ningún tipo de fruta fresca, ni verduras, ni hortalizas, a excepción de tomates (en muy poca cantidad) y de cebolla larga, que añaden cuando cocinan el arroz. La alimentación diaria en general es escasa y hay muy poca variedad de productos (Daza y Tobar, 2006).

Así como para los niños, para los adultos el desayuno también consiste en un vaso de frutiño o de agua de panela. La cena es servida hacia las cuatro o cinco de la tarde para todos los miembros de la familia y consiste, igualmente, en un vaso de frutiño o agua de panela (Daza y Tobar, 2006). Estas bebidas las utilizan todo el día para refrescarse, ya que viven en un lugar que constantemente tiene altas temperaturas. Ellos están acostumbrados, pero para las personas ajenas a la comunidad, los alijunas, estas temperaturas son difíciles de soportar. El almuerzo, a mediodía, es plátano frito y arroz y, cuando lo hay, pescado frito. No comen nada más. 
Las mujeres de esta comunidad no cultivan maíz. Por lo tanto, no elaboran la chicha de maíz, que es una bebida muy tradicional en todo el resto de las comunidades indígenas de Colombia.

Los niños wayú siguen presentando los índices de desnutrición aguda y crónica más alta de toda Colombia. La estatura y el peso de los niños no se corresponden en general con la edad.

La mayoría de los niños tiene caries, problemas de parasitismo intestinal, infecciones de las vías respiratorias altas, piojos, enfermedades de la piel tales como sarna e infecciones producidas por picaduras de insectos (Daza y Tobar, 2006).

\section{Valoración nutricional de los productos más consumidos en la comunidad}

\section{Frutiño}

Una porción equivale a 2 vasos $(400 \mathrm{~mL})$

Calorías: $3 \mathrm{kcal}$ en $100 \mathrm{~g}$

Hidratos de carbono: $1,00 \mathrm{~g}$

Proteína: $0,00 \mathrm{~g}$

Vitamina B1: 0,075mg x porción

Vitamina C: 4,5 mg x porción

Ingredientes: azúcar, acidulantes (ácido cítrico o fumárico o málico), edulcorantes artificiales (aspartamo, acesulfame de potasio y sacarina), sabor artificial, estabilizante, anticompactante (fosfato tricálcico), enturbiante trióxido de titanio), pulpa deshidratada de fruta (dependerá del sabor, pero es solo 0,05\%), colorantes artificiales, vitamina C y vitamina B1.

\section{Panela}

Valor nutricional (por cada 100 gramos):

Calorías: $351 \mathrm{kcal}$

Hidratos de carbono: $80 \mathrm{~g}$

Proteínas: $0,7 \mathrm{~g}$ 
Fibra: $0,27 \mathrm{~g}$

Grasa: $0,14 \mathrm{~g}$

Calcio: $204 \mathrm{~g}$

Hierro: $5 \mathrm{mg}$

Fósforo: $66 \mathrm{mg}$

Potasio: $165 \mathrm{mg}$

Producto derivado de la caña de azúcar compuesta por agua y sacarosa. La panela es un alimento nutritivo ya que no pierde sus minerales y vitaminas durante el tratamiento, como sucede con el azúcar que es la continuación del procedimiento. Su precio varía según el peso, la textura, el color, y el sabor, pero en general es barato y constituye el principal alimento del pueblo wayú. En Colombia una panela de 450 gr puede costar unos 1100 pesos (0,26 euros aproximadamente). Se consume como bebida llamada "agua de panela", esta se obtiene al disolver un pedazo de panela en agua hirviendo. Se utiliza como endulzante para el café o el chocolate y también para hacer dulces caseros. Se le atribuyen, además, propiedades curativas en heridas como cicatrizante (panela rayada) - en enfermedades del aparato respiratorio como la bronquitis (agua de panela con limón caliente)- y en enfermedades del hígado.

\section{Bienestarina}

Valor nutricional por cada 100 gramos:

Energía: $348 \mathrm{kcal}$

Proteínas: $23 \mathrm{~g}$

Carbohidratos: $54 \mathrm{~g}$

Grasa: 4,50 g

Vitamina A: 4500 I. U.

Tiamina: $170 \mathrm{mg}$

Riboflavina: $1 \mathrm{mg}$

Niacina: $13,50 \mathrm{mg}$

Calcio: $300 \mathrm{mg}$ 
Hierro: $11 \mathrm{mg}$

Fosforo: $68 \mathrm{mg}$

La Bienestarina ${ }^{\circledR}$ es una mezcla vegetal (maíz, soja, trigo) en forma de harina, enriquecida con vitaminas y minerales. Aporta micronutrientes y proteínas. Es la harina que regala el Gobierno nacional a los niños pobres de Colombia con problemas de desnutrición crónica y aguda.

\section{Conclusiones}

Los indígenas wayú de La Guajira tienen costumbres muy arraigadas a pesar del paso del tiempo. La manera como consideran que deben vivir continúa siendo necesaria para ellos. Estas tradiciones y hábitos no les permiten consumir ciertos animales que crían, como el cerdo, el pollo y la gallina. Solo los utilizan para venderlos en la plaza del mercado y con este dinero comprar en la tienda de Fidelina otros productos, para ellos, básicos, como el frutiño. Los chivos, que sí consumen y a veces crían, los utilizan únicamente para ocasiones especiales, como la dote de una hija o un funeral. El chivo es símbolo de riqueza, respeto y poder. Por estas creencias no consumen la suficiente proteína ni los nutrientes necesarios que sus organismos requieren para poder tener un crecimiento óptimo. La poca proteína que ellos consumen, y únicamente en algún día de la semana, proviene del pescado. Las condiciones climáticas en que viven, una zona semidesértica, no les ayudan para que cultiven productos de primera necesidad y tener una alimentación sana, con suficientes cereales, legumbres, frutas, verduras y hortalizas.

Con este texto me propuse dar a conocer cómo viven los indígenas wayú, sus costumbres, sus creencias, sus tradiciones. Esta es una comunidad importante y extensa que, por todos sus problemas de salud pública, tiende a desaparecer. Considero que los wayú aún tienen mucho para enseñarnos y por eso me gustaría que todos se interesaran por su historia actual. 


\section{Bibliografía}

Brazelton, T., y Greenspan, S. (2005). Las necesidades básicas de la infancia. Barcelona: Graó.

Buen, I. (2004). Comedores escolares: Mucho más que un menú. Padres y maestros 284 , 18-21.

Recuperado

de https://revistas.comillas.edu/index.php/padresymaestros/article/view/1947

Daza, B., y Tobar, L. F. (2006). Los niños indígenas wayú del desierto: Cultura y situación alimentaría. Bogotá: Pontificia Universidad Javeriana - Facultad de Nutrición.

García, D. M. (2003). Cultura alimentaria. RESPYN: Revista de salud pública y nutrición, 4(3). Recuperado de http://respyn.uanl.mx/index.php/respyn/article/view/112/95 